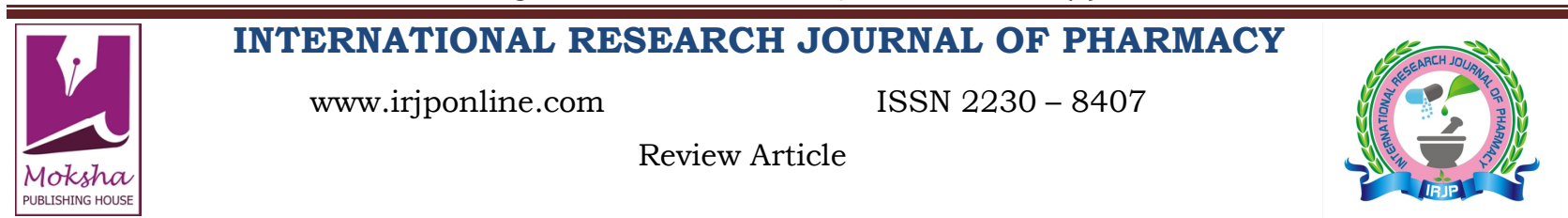

\section{TRANSDERMAL DRUG DELIVERY ADHESION AS A CRITICAL PARAMETER}

Singh Mahavir*, Sareen Rashmi

School of Pharmaceutical Sciences, Shoolini University, Solan, Himachal Pradesh, India

*Corresponding Author Email: mahisilverine@gmail.com

Article Received on: 12/08/13 Revised on: 07/09/13 Approved for publication: 13/09/13

DOI: 10.7897/2230-8407.04905

IRJP is an official publication of Moksha Publishing House. Website: www.mokshaph.com

(C) All rights reserved.

\section{ABSTRACT}

Transdermal drug delivery system (TDDS), also known as "patches", are the dosage forms designed to deliver a therapeutically effective amount of drug across a patient's skin. The adhesive of the transdermal drug delivery system is very crucial to the safety, efficacy and quality of the product. Recently, it has been recognized that the skin can also serve as the port of administration for systemically active drugs. The drugs applied topically are first absorbed into the blood stream and then are transported to the target tissues. Now, it is becoming evident that the benefits of intra venous infusion can be closely duplicated by using skin as the port of drug administration to provide continuous transdermal drug infusion into the systemic circulation. One of the objectives of TDDS is the maintenance of blood concentration of drug at therapeutic level by means of controlled permeation throughout the skin during a long period of time and using only one administration. The drug input can be terminated at any point of time by just removing the patch. Rate of drug release from the TDDS is normally much greater than the amount that the skin can possibly absorb. Hence, even if there is a variation in skin permeability, a constant rate of drug input into the circulation is achieved. This article provides an overview of type of transdermal systems, role of adhesion, possible adhesion failures and the measurement of adhesion. In vitro techniques like peel adhesion, tack and shear strength are discussed. Adhesion needs to be a critical parameter for designing a transdermal drug delivery system in order to provide good quality and efficacy to the patient. This review also covers a brief outline of various components of a patch, their advantages, when the patch should be used and when their use should be avoided.

Keywords: Transdermal drug delivery system, adhesion, iontophoresis, sonophoresis, electroporation.

\section{INTRODUCTION}

Transdermal drug delivery system is the system in which the delivery of the active ingredients of the drug occurs by the means of skin. Transdermal drug delivery system is the method that can effectively and painlessly deliver large molecules in therapeutic ranges to overcome the difficulties that are associated with oral and other routes. In transdermal drug delivery system, skin is the medium from where the drug is being absorbed and finally the drug reaches the circulatory system. These transdermal patches have been proved to be more effective because of their large advantages over other controlled drug delivery systems. A transdermal patch is a medicated adhesive patch that is placed on the skin to deliver a time-released dose of medication through the skin to treat systemic conditions. Transdermal therapeutic system (TTS) has been available commercially since the early 1980's. In a broad sense, the term transdermal delivery system includes all topically administered drug formulations intended to deliver the active ingredient into the general circulation ${ }^{1}$. The major aim of transdermal drug delivery system is to provide a controlled and continuous delivery of drugs via skin to the systemic circulation. It overcomes various side effects like painful delivery of drugs and first pass metabolism of drugs occurred with other routes of drug delivery systems ${ }^{2,3}$. Hence, this system has been a great field of interest in the recent time. The drug is delivered to the skin with the help of a patch which adheres to the skin. The main advantage of this system is that there is a controlled release of the active medicament and the medication is painless. Absorption of drug through the skin is affected by a number of factors such as skin sites, skin thickness, skin temperature, body temperature, blood flow, lipid concentration, number of hair follicles, skin cleansing, hydration status, sweat gland function, ethnic group, $\mathrm{pH}$ of skin surface and integrity of the stratum corneum ${ }^{4-6}$. A transdermal patch has several components like liners, adherents, drug reservoirs, drug release membrane etc. It has become a highly research field because of its great advantages. A transdermal patch or a skin patch is a medicated adhesive patch that is placed on the skin to deliver a specific dose of medication through the skin and into the blood stream. The first prescription patch was approved by U.S. Food and Drug Administration in 1979, which administered Scopolamine for motion sickness.

\section{Components of a transdermal patch}

- Liner- protects the patch during storage. The liner is removed prior to use and it should be chemically inert.

- Drug- drug solution is in direct contact with the release liner ${ }^{7}$.

- Adhesive- to adhere the components of the patch together along with adhering the patch to the skin surface e.g. Poly-isobutylene, acrylics, silicones etc.

- Membrane- controls the release of the drug from the reservoir and multilayer patches. It is diffusion properties are used to control availability of drug or excipients to skin.

- Backing- protects the patch from outer environment and gives appearance, flexibility to the patch. e. g. Polyester films, polyethylene films, poly-olefin films etc ${ }^{8}$.

- Penetration enhancer- modulates the skin permeability in some fashion. e. g. Propylene glycol, methyl laurate, ethyl oleate, carvone, lauric acid etc.

\section{Transdermal patch design}

In almost all transdermal patch designs, the drug is stored in a reservoir that is enclosed on one side with an impermeable backing and has an adhesive that contacts the skin on the other side 9 . Some designs employ drug dissolved in a liquid or gel-based reservoir, which can simplify formulations and permit the use of liquid chemical enhancers, such as ethanol. These designs characteristically are composed of four layers: an impermeable backing membrane; a drug reservoir; a semi permeable membrane that may serve as a rate-limiting barrier; and an adhesive layer. Other designs incorporate the 
drug into a solid matrix, which simplifies manufacturing. Matrix system can have three layers, by eliminating the semipermeable membrane, or just two layers, by incorporating the drug directly into the adhesive.

\section{Drug selection criteria}

- The drug should have a molecular weight less than approximately 1000 Daltons.

- The drug should have affinity for lipophilic and hydrophilic patches.

- The drug should have a low melting point.

- The drug should be effective in a low daily dose.

- The half life of the drug should be short.

- The drug should not induce an allergic response.

- The tolerance to the drug should not develop under nearly zero-order release profile of trans dermal system.

Conditions in which transdermal patches are used

A transdermal patch is used when:

- The patient has intolerable side effects and is requesting another method of drug delivery.

- The pain control might be improved by reliable administration.

- It can be used with other enhancement strategies to produce synergistic effects ${ }^{10}$.

Conditions when transdermal patches are not used

The use of transdermal patch is not suitable when:

- Cure for acute pain required.

- Rapid dose titration is required.

- Requirement of dose is equal to or less than $30 \mathrm{mg} / 24$ $\mathrm{h}^{11}$.

\section{Care taken while applying a patch}

e part of skin where the patch has to be applied must be properly cleaned.

e patch should not be cut because doing this will destroy the drug delivery system.

- New patch should be applied only after removing the previous one ${ }^{12}$.

- The patch should be applied accurately on to the administration site.

- Care must be taken while applying or removing a patch because uneven handling of the patch may cause absorption of drug before the application of the patch.

\section{Mechanism of Action of a Transdermal Patch}

The application of the patch and the flow of the active drug from patch to blood stream via skin occur through various methods.

\section{Iontophoresis}

By passing a few miliamperes of current to a few square centimeters of skin through the electrodes placed in contact with the formulation, the drug delivery across the barrier is facilitated $^{13}$. For rapid onset of anesthesia the iontophoretic delivery of lidocaine is a promising approach. Pilocarpine is also given by this method in some cases ${ }^{14}$. Iontophoresis has been studied for moto increase transdermal delivery for more than a century by typically applying a continuous low-voltage current $^{15}$. While there can be increased skin permeability, iontophoresis provides an electrical driving force for transport across stratum corneum. Charged drugs are moved via electrophoresis, while weakly charged and uncharged compounds can be moved by electro-osmotic flow of water generated by the preferential movement of mobile cations instead of fixed anions in the stratum corneum ${ }^{16}$. Iontophoresis does not change the skin barrier itself; it is mostly applicable to small molecules that carry a charge and some macromolecules up to a few thousand daltons. The strongest asset of iontophoresis is that the rate of drug delivery scales with electric current, which can be readily controlled by a microprocessor or, in some cases, the patient $^{17}$. In this way, drug delivery can be turned on and off and even modulated over time to enable complex delivery profiles. However, the maximum current- and therefore the maximum delivery rate- are limited by skin irritation and pain caused by the general inability of iontophoresis to localize its effects to the stratum corneum.

\section{Electroporation}

In this technique, short, high voltage pulses are applied on to the skin. By this, the diffusion permeability of the skin is increased by four orders of magnitude ${ }^{18,21}$. These electrical pulses form transient aqueous pores in the stratum corneum and the drug can easily transport through these pores ${ }^{19}$. By using closely spaced electrodes the applied electric field can be constrained within the nerve-free stratum corneum and the electrical pulses can be administered painlessly ${ }^{20}$. Hence this method is safe. Electroporation is well known as a method to reversibly disrupt cell membranes for gene transfection and other applications. Electroporation is also found to disrupt lipid bi layer structures in the $\operatorname{skin}^{22}$. As the stratum corneum has greater electrical resistance than the deeper tissues, the electric field applied during electroporation is initially concentrated in the stratum corneum ${ }^{23}$. Upon electroporation of stratum corneum lipid bi layer, its electrical resistance drops down and this field is then distributed into the deeper tissues, which contain sensory and motor neurons. The associated pain and muscle stimulation can be avoided by using closely spaced microelectrodes that constrain the electric field within the stratum corneum ${ }^{24}$.

\section{Sonophoresis}

Sonophoresis is the enhancement of migration of drug molecules through the skin by ultrasonic energy. In this technique we use ultrasound, particularly low frequency ultrasound waves. Acoustic waves of particular frequency reduce the resistance offered by the stratum corneum. This technique increases transdermal transport of various drugs including macromolecules. Katz et al. reported on the use of low frequency sonophoresis for topical delivery of EMLA cream $^{25}$. Some of the drugs given by this method are Dexamethasone, Ibuprofen, Hydrocortisone, Indomethacin, Phenyl butazone etc. Ultrasound was first widely recognized as a skin permeation enhancer when physical therapists discovered that massaging anti-inflammatory agents into the skin using ultrasonic heating probes increased efficacy ${ }^{26}$. The pressure gradient and oscillations associated with ultrasound act as a driving force to move drugs into the skin. It appears that the effect is to disrupt stratum corneum lipid structure and thereby increase skin permeability. Associated tissue heating that is not targeted to the stratum corneum can damage deeper tissues ${ }^{27}$. 
Use of microscopic projections

Transdermal patches with microscopic projections called micro needles are used to facilitate the transdermal drug transport. Needles ranging from $10-100 \mu \mathrm{m}$ in length are arranged in arrays ${ }^{28}$. When pressed into the skin, these arrays make microscopic punctures that are large enough to deliver macromolecules and small enough that the patient does not feel pain. The drug is coated on the surface of the micro needles to help in rapid absorption ${ }^{29-31}$. This method is mainly used for cutaneous vaccines for tetanus and influenza ${ }^{32}$.

\section{Micro needles}

- Increase skin permeability by creating micron-scale pathways in the skin $^{33}$.

- Can actively drive drugs into the skin either as coated or encapsulated cargo introduced during micro needle insertion.

- Target their effects to the stratum corneum, although micro needles typically pierce across the epidermis and into the superficial dermis too ${ }^{34,35}$.

\section{Thermal Ablation}

Thermal ablation selectively heats the skin surface to generate micron scale perforations in stratum corneum ${ }^{36}$. Heating the skin surface to hundreds of degree for microseconds to milliseconds localizes heat transfer to the skin surface without allowing the heat to propagate to the viable tissues below ${ }^{37}$. Most recent studies suggest that temperature well above the boiling point of water is needed for this purpose ${ }^{38}$. Skin heating is achieved by ohmic micro heaters and radiofrequency ablation ${ }^{39}$.

\section{Microdermabrasion}

Final way to remove stratum corneum barrier employs abrasion by microdermabrasion or by simple sandpaper ${ }^{40}$. This abrasive mechanism which is related to sand blasting on the microscopic scale has been shown to increase skin permeability to drugs like lidocaine, 5- fluorouracil, which suggests possible applications in $\operatorname{TDDS}^{41}$.

\section{Recent Techniques Used in TDDS Poroplastic membrane}

The poroplastic membrane is an open cell ultra microporous form of cellulose triacetate. It holds the saturated drug solution by capillary action. The main advantage of this type of system is that their diffusive permeability can be varied over a wide range.

\section{Use of hydrophilic gel matrix over the polymeric} transdermal system

The matrix is an "open cell molecular sponge". The plasticizer contains the drug in a soluble or suspended state in a micro space. It also contains a mixture of hydrogen bonding liquids like water, glycerin, polyethylene glycol, polypropylene glycol etc.

\section{Types of Transdermal Patches}

\section{Single - layer drug - in- adhesive}

In this type of system, drug is present in the adhesive layer. The adhesive layer serves to adhere the various layers together and also helps in adhesion of entire system with the skin. This adhesive layer is also responsible for the release of drug from this system. The adhesive layer is surrounded by a temporary liner and a backing layer ${ }^{42}$.
Multi - layer drug - in adhesive

This patch is similar to single-layer system that in both adhesive layers is responsible for the release of the active drug. This multi-layer system is different however, that it adds another layer of drug in adhesive, usually separated by a membrane. This patch also has a temporary liner and a permanent backing layer.

\section{Reservoir}

This system is different from previous two systems. Reservoir system has a separate drug layer. The drug is present in the form of solution or suspension separated by the adhesive layer. The rate of release of drug from reservoir type of system is zero order.

\section{Matrix system}

The matrix system has a drug layer of a semisolid matrix containing a drug solution or suspension. Drug layer is surrounded by the adhesive layer. Nitroglycerine releasing system is an example of matrix type of system. Main advantage of this system is that the dose dumping cannot occur with this system.

\section{Vapor patch}

In this patch, the adhesive layer not only serves to adhere various layers together but also to release vapors. Vapor patch are new on the market and they release essential oils for up to $6 \mathrm{~h}$. These are mainly used in decongestion. Vapor patches are also used to improve the quality of sleep. Such patches are known as controller patches. Vapor patches are also used to decrease the quantity of cigarettes that a person smokes in a month.

\section{Rising Interest in Transdermal Vaccines}

TDDS offers compelling opportunities to improve vaccine administration $^{46}$. Vaccine delivery via skin is more attractive because it targets the potent epidermal langerhans and dermal dendritic cells that may generate a strong immune response at much lower doses than deeper injections ${ }^{47}$. Elimination of the need for hypodermic needles motivates transdermal vaccine development. In a world where needle reuse kills at least 1.3 million people per year from hepatitis B and AIDS, needle free, patch based vaccination could have large impact ${ }^{48}$. Excitement about this approach is exemplified by completion of phase 3 trials and submission for registration in Europe by Sanofi Pasteur (Paris) and Becton Dickinson for their micro needle based influenza vaccine ${ }^{49}$.

\section{Three Possible Generations of TDDS in Future}

- First generation- that produced many of the today's patches by judicious selection of drugs that can cross the skin at therapeutic rates with little or no enhancements ${ }^{51}$.

- Second generation- that has yielded additional advances for small molecule delivery by increasing skin permeability.

- Third generation- that will enable transdermal delivery of small molecule drugs, macromolecules and vaccines etc. by targeted permeabilization of the stratum corneum ${ }^{52}$.

\section{Ideal Properties of Adhesives to be Used in TDDS}

- It should not sensitize or irritate the skin during its contact time with the skin.

- It should aggressively adhere to the skin and its position should not get disturbed during bathing, exercise etc. 
- It should be easy to remove.

- It should not leave any residue on the skin after its removal.

- It should have good physical and chemical compatibility with drug, excipients, penetration enhancers used in the TDDS.

- It should not affect the permeation of the drug.

\section{Role of Adhesion in Drug Delivery}

Adhesion or lack of adhesion of transdermal system is a very critical factor and has a direct effect on therapeutic action of the active drug. Absorption process is related to the drug partitioning between the transdermal drug delivery system and the $\operatorname{skin}^{53}$. So, a complete skin contact with the delivery system is required for the labeled time period. If the TDDS partially detaches, then effective area of TDDS/skin contact changes and finally the drug absorption changes in an unpredictable manner ${ }^{54}$. This can lead to therapeutic failure. Consistent delivery and absorption of the active drug is achieved only when the patch is in proper contact with the skin for the labeled time period. So the quality of contact between patch and skin is directly related to the consistency of drug delivery. Ginn et al. reported that clean and dry skin has a surface energy about $27 \mathrm{dyn} / \mathrm{cm}$. So, surface energy of the TDDS should be less than the lowest critical surface energy value reported for skin. This is a necessary but not sufficient condition for adhesion. Some other conditions are wetting rate and visco elasticity of the adhesive. After applying a transdermal patch, an increase in adhesion is mainly related to the visco elastic flow of the adhesive because it warms the skin $^{55}$. Most commonly used adhesives in TDDS are polyisobutylenes, acrylics, silicones etc.

\section{Modes of Failure in Transdermal Drug Delivery System}

When the patch is peeled, it is expected that it will strip cleanly from the skin, leaving no visible residue. This type of failure is an adhesive failure, case 1 . If the adhesive transfer to the skin, leaving no adhesive on the TDDS, this type of failure is an adhesive failure, case 2. Cohesive failure, case 3, is when adhesive is left on the TDDS and on the skin. Based on the type of failure mode, it is possible to find out the potential cause of the failure ${ }^{56}$.

\section{Techniques to Measure Adhesive Properties}

The adhesive action of TDDS is a critical factor as it determines its drug delivery, therapeutic action, patient compliance. Several in vitro techniques are used to monitor adhesive action such as peel adhesion, tack property and shear strength measurement ${ }^{57}$. These are not true material properties because they depend upon the substrate, backing material and test parameters. The adhesive property of the TDDS must be measured in its final form to ensure acceptable adhesive quality ${ }^{58}$.

\section{Peel Adhesion}

Peel adhesion measures the force required to peel away an adhesive once it has been attached to a surface. Recently used test methods for TDDS peel adhesion are based on methods developed for industrial tapes. In these methods stainless steel panel, skins, HDPE are used as substrates. Peel angle must be $90^{\circ}$ or $180^{\circ}$. Sample must be cut into exact width, dwell time of one minute and a peel speed of $300 \mathrm{~mm} / \mathrm{min}$ is required $^{59}$. The peel adhesion measurement is greatly influenced by the experimental parameters like dwell time, substrate, peel angle, peel speed etc. Peel adhesion measurement also depends on the TDDS backing and adhesive thickness.

\section{Tack Property}

Initially, the tack property of an adhesive was evaluated by "thumb test". Then probe tack test was developed in order to refine and stimulate thumb test ${ }^{60}$. In probe tack test, a probe touches the adhesive surface with a light pressure and the force required to break the bond after a short time period of contact is measured. Tack property is not just a function of the material properties of the adhesive but also depends on the experimental parameters ${ }^{61}$. It depends upon the contact area, the contact pressure, time of contact, rate of separation and test environment. Tack test is relative to both the substrate material and the sample adhesive.

\section{Shear Adhesion}

It is also known as the creep compliance. It is a measure of the cohesive strength. Higher shear adhesion indicates a lower cohesion. This can be observed by the TDDS leaving the adhesive residue on the outer edges of the TDDS, liner or pouch $^{61}$. The adhesive residue from the cold flow or "creeping" of the TDDS may contain drug if the system is a type that contain drug in adhesive. This cold flow will make it difficult for the patient to remove TDDS from the release liner. Low creep compliance is desirable; however, too low of a value leads to the loss of tack and peel adhesion. Hence, the adhesive must exhibit an elastic cohesiveness and a resistance to flow under stress ${ }^{62}$.

\section{Scoring system for a TDDS}

$0=90 \%$ adhered (no lift off the skin)

$1=75 \%$ to $<90 \%$ adhered (some edges only lifting off the skin)

$2=50 \%$ to $<75 \%$ adhered (less than half of the system lifting off the skin)

$3=<50 \%$ adhered but not detached (more than half the system lifting off the skin without falling off the skin)

$4=$ patch detached (patch completely off the skin)

\section{Future Outlook}

Looking to the future, it is likely that first- generation patch technology will continue to be used for delivery of small molecule drugs with the right set of properties, especially those drugs that are currently administered orally and by injection that are coming off patient. Second generation chemical enhancers should find continued use as formulation excipients in dermatological creams and ointments and some systemic patches for small molecule drugs. They will probably have a little impact on delivery of hydrophilic drugs and macromolecules because generally the most effective chemical enhancers diffuse out of the stratum corneum and irritate deeper tissues. Third generation chemical enhancers offer strategies for more targeted enhancements, but are still in early stages of development. Second- generation physical enhancement using iontophoresis has already made clinical impact, especially for rapid, localized delivery to skin. It provides controlled drug dosing to the patient. Iontophoresis along with some other methods may find use in the delivery of macromolecule or vaccines. Non-cavitational ultrasound has found use for transdermal delivery of anti-inflamatories, but does not appear to be suitable for delivery of large molecules. Third generation physical enhancement using cavitational ultrasound and electroporation enhance 
transdermal delivery by disrupting stratum corneum on the nanometer scale. Cavitational ultrasound has already been approved for transdermal delivery of lidocaine and may be approved for peptides and other small molecules in future. Third generation methods appear to be more promising because they appear capable of delivering small molecules, macromolecules and vaccines as well. Published data suggests that these methods can be safe and effective. Moreover, unpublished clinical trials appear to yield promising results. Overall, transdermal drug delivery offers compelling opportunities to address the low bioavailability of many oral drugs, the pain and inconvenience of injections. First-generation patches, second- generation chemical enhancers and iontophoresis are expanding delivery capabilities for small molecules. Third-generation physical enhancers could enable transdermal delivery of macromolecules and vaccines. These scientific and technological advances that enable targeted disruption of stratum corneum while protecting deeper tissues have brought the field to a new level of capabilities that position transdermal drug delivery for increasingly widespread impact on medicine.

Table 1: Transdermal products that are in clinical development in the United States

\begin{tabular}{|c|c|c|}
\hline Compound & TDD technology & Development stage \\
\hline Alprostadil & Gel & Preclinical \\
\hline Buprenorphine & Patch & Phase 3 \\
\hline Dexamethasone & Iontophoresis & Phase 3 \\
\hline Dextroamphetamine & Patch & Preclinical \\
\hline Diclofenac & Patch & Preclinical \\
\hline Dihydrotestosterone & Gel & Phase 3 \\
\hline Estradiol & Gel & Phase 3 \\
\hline Androgen/Estradiol & Patch & Phase $2^{44,45}$ \\
\hline
\end{tabular}

Table 2: Expected effects of skin delivery system on horny layer hydration and skin permeability

\begin{tabular}{|c|c|c|c|}
\hline Delivery system & Examples/constituents & Effect on skin hydration & Effect on skin permeability \\
\hline Occlusive dressing & Plastic film, imperforated waterproof plaster & Prevents water loss; Full hydration & Marked increase \\
\hline Occlusive patch & Most transdermal patches & Prevents water loss; Full hydration & Marked increase \\
\hline
\end{tabular}

\section{CONCLUSION}

Currently, many of the clinical trials uses placebo patches to determine the adhesion performance of new drug products. Adhesion properties of TDDS depend on type and concentration of drug used, compatibility of drug with excipients and with the components of TDDS. Some patient instructions allow for taping of edges of a patch that is lifting. The patch should be manufactured in such a way that it does not fall off over the entire period of application. Novel dosage forms are developed to target drug delivery, better patient compliance, decrease toxicity. Novel dosage forms must be stability indicating, assure best consistency, product performance and they must be reproducible. TDDS are novel dosage forms which mainly rely on food adhesion over a period of many hours or days to ensure proper drug delivery. Skin adhesion is one of the most important functional properties for a TDDS. Poor adhesion results in improper dosing of patients. Consistent methodology to test the adhesion properties of TDDS and ensure their safety does not exist; although, in vivo human skin testing is the most reliable method for TDDS evaluation. So, it is important to develop in vitro adhesion testing methods. It is desirable that the vitro adhesion testing co-relates with in vivo skin adhesion. The adhesion of a TDDS needs to be a part of the upfront design of the transdermal drug delivery system.

\section{REFERENCES}

1. Ranade V. Drug delivery systems: Transdermal drug delivery. The Clinical Journal of Pharmacology 2001; 6: 13-19.

2. ISMP, Little Patches, big problems, Institute for safe Medication Practice: Medication Safety Alert 2005; 4: 1-3.

3. Janseen. Dear Healthcare Professional letter 2005: 5.

4. Spencer TS, Smith SE, Conjeevaram S. Adhesive interactions between polymers and skin in transdermal delivery systems, Poly. Mater. Sci. Eng 1990; 63: 337-339.

5. Ashburn MA, Ogden LL, Zhang J, Love G, Basta SV. The pharmacokinetics of transdermal Fentanyl delivered with and without controlled heat. An overview; 2003. p. 291-297. Available from URL: http://www.pharmatutor.com.
6. Wester RC, Maibach HI. Clinical considerations for transdermal delivery, in Kydonieus AF, Berner B (eds.). Transdermal Delivery of Drugs, vol.1, CRC Press, Boca Raton, FL 1987; 1: 71-78.

7. Jacoby, David B, Youngson RM, Marshall Cavendish Corporation. Encyclopedia of Family Health, Published by Marshall Cavendish; 2004. p. 2259-2267.

8. Bayarski, Yuri. Transdermal Drug Delivery, Transdermal Patches. International Biopharmaceutical Association Publication; 2009. p. 941958 .

9. Food and Drug Administration. Ed $27^{\text {th }}$. Rockville MD. Department of Health and Human Servics 2007; 13:8:34.

10. Guy, Richard H, Hadcraft, Jonathan. Transdermal Drug Delivery Second Edition Published by Informa Health Care; 2002. p. 322-336. http://dx. doi.org/10.1201/9780203909683

11. Arcangelo, Virginia P, Peterson, Andrew M. Pharmaco therapeutics for Advanced Practice, Published by Lippincott Williams єt Wilkins; 2005. p. 74-79.

12. Elling, Bob, Kirsten M, Rothenberg, Mikel A. Why-Driven EMS Enrichment, Published by Thomson Delmar Learning; 2001. p. 103-109.

13. Kushwaha P, Fareed S, Nanda S. Colonic drug delivery: An overview. Intern J Pharma Res Develop 2010; 2(4): 1-10.

14. Colonic Delivery Formulations. Recent Patents on Drug Delivery and Formulation 2007; 1(1): 55-59.

15. Basit AW, Podczeck F, Newton JM. Use of formulation technology to assess regional gastrointestinal drug absorption in humans. Eur. J. Pharm. Sci 2004; 21: 179-189. http://dx.doi.org/10.1016/j.ejps.2003. 10.003 PMid: 14757489

16. Kalia YN, Naik A, Garrison J, Guy RH. Iontophoretic drug delivery 2004; 56: 619-658.

17. Pikal MJ. The role of electro osmotic flow in transdermal iontophoresis 2001; 46: 281-305.

18. Electroporation from wikipedia, the free encyclopedia available from URL: http:// Wikipedia.org/wiki/electroporation.

19. Neumann E, Schaefer M, Wang Y, Hofschneider PH. Gene transfer into mouse lyoma cells by electroporation in high electric fields. EMBO J. 1(7): 841-850. PMid:6329708 PMCid:PMC553119

20. Sugar IP, Neumann E. Stochastic model for electric field-induced membrane pores Electroporation, Biophysical. Chem 19; 3: 211-225. http://dx.doi.org/10.1016/0301-4622(84)87003-9

21. Sarah Yang. New medical techniques punches holes in cells, could treat tumors 2007; 2: 12.

22. Denet AR, Vanbever R, Preat V. Skin electroporation for transdermal and topical delivery. Advanced Drug Delivery Review 2004; 56: 659674. http://dx.doi.org/10.1016/j.addr.2003.10.027 PMid:15019751

23. Anil K, Philip B. Colon targeted drug delivery systems, a review on primary and novel approaches. Oman Med J. April 2010; 25(2): 70-78. 
http://dx doi.org/10.5001/omj.2010.24 PMid:22125706 PMCid:PMC3 215502

24. Pliquett U, Weaver JC. Feasibility of an electrode-reservoir device for transdermal drug delivery by non invasive skin electroporation. IEEE Trans Biomed Eng 2007; 54: 536-538. http://dx.doi.org/10.1109/ TBME.2006.886828 PMid:17355067

25. Basit AW, Podczeck F, Newton JM. The use of formulation technology to assess regional gastrointestinal drug absorption in humans. European Journal of Pharmaceutics 2004; 21: 179-89. http://dx.doi.org/10.1016 /j.ejps.2003.10.003

26. Machet L, Boucaud A. Phonophoresis: efficiency, mechanisms and skin tolerance. Int. J Pharm 2002; 2: 1-15. http://dx.doi.org/10.1016/S03785173(02)00299-5

27. Wu J, Nyborg W. editors London: Imperial College Press, Emerging Therapeutic Ultrasound 2006; 10: 13-18.

28. Anil K, Philip B. Colon targeted drug delivery systems: A review on primary and novel approaches. Oman Med J 2010; 25(2): 70-78. http://dx.doi.org/10.5001/omj.2010.24PMid:22125706 PMCid:PMC3 215502

29. Sivamani RK, Liepmann D, Maibach HI. Micro needles and transdermal applications. Expert Opin Drug Deliv 2007; 4: 19-25. http://dx. doi.org/10.1517/17425247.4.1.19 PMid:17184159

30. Prausnitz MR, Gill HS, Park JH. Modified Release Drug Delivery. In: Rathbone MJ, Hadgraft J, Roberts MS, Lane ME, editors. New York: Informa Healthcare 2008; 12: 25-38.

31. Gill HS, Prausnitz MR. Coated micro needles for transdermal delivery. J Control Release 2007; 117: 227-237. http://dx.doi.org/10.1016/j.jconrel 2006.10.017 PMid:17169459 PMCid:PMC1853346

32. Lee JW, Park JH, Prausnitz MR. Dissolving micro needles for transdermal drug delivery. Biomaterials 2008; 29: 2113-2124. http://dx.doi.org/10.1016/j.biomaterials.2007.12.048 PMid:18261792 PMCid:PMC2293299

33. Wermeling DP. Micro needles permit transdermal delivery of a skinimpermeant medication to humans. Proc Natl Acad Sci USA 2008; 105 2058-2063. http://dx.doi.org/10.1073/pnas.0710355105 PMid:18250310 PMCid:PMC2538880

34. Kamel AH. Oral colon targeted delivery systems for treatment of inflammatory bowel diseases: synthesis, in vitro and in vivo assessment. Intern J Pharm 2008; 358: 248-255. http://dx.doi.org/10.1016/j.ijpharm. 2008.04.021 PMid:18502065

35. Laurent PE. Evaluation of the clinical performance of a new intra dermal vaccine administration technique and associated delivery system 2007 ; 25: $8833-8842$.

36. Bramston J. Enabling topical immunization via microporation: a nove method for pain-free and needle-free delivery of adenovirus-based vaccines. Gene Ther 2003; 10: 251-260. http://dx.doi.org/10.1038 /sj.gt.3301886 PMid:12571633

37. Levin G. Transdermal delivery of human growth hormone through RFmicro channels. Pharm Res 2005; 22: 550-555. http://dx.doi.org/10.1007 /s11095-005-2498-6 PMid:15846462

38. Park JH, Lee JW, Kim YC, Prausnitz MR. The effect of heat on skin permeability. Int J Pharm 2008; 359: 94-103. http://dx.doi.org/10.1016 /j.ijpharm.2008.03.032 PMid:18455889 PMCid:PMC2464624

39. Badkar AV, Smith AM, Epstein JA, Banga AK. Transdermal delivery of interferon alpha-2B using microporation and iontophoresis in hairless rats. Pharm Res 2007; 24: 1389-1395. http://dx.doi.org/10.1007/s11095007-9308-2 PMid:17443396

40. Herndon TO, Gonzalez S, Gowrishankar T, Anderson RR, Weaver JC. Transdermal micro conduits by micro scission for drug delivery and sample acquisition. BMC Med 2004; 2-12.

41. Glenn GM. Transcutaneous immunization with heat-labile enterotoxin: development of a needle-free vaccine patch. Expert Rev. Vaccines 2007; 6: 809-819. http://dx.doi.org/10.1586/14760584.6.5.809 PMid:17931160

42. Sinha VR, Kumria R. Microbially triggered drug delivery to the colon. European journal of pharmaceutical sciences 2003; 18(1): 3-18. http:// dx.doi.org/10.1016/S0928-0987(02)00221-X
43. Finnin BC, Morgan TM. Transdermal penetration enhancers: applications, limitations, and potential. J Pharm Sci 1999; 88(10): 955958. http://dx.doi.org/10.1021/js990154g PMid:10514338

44. Guy RH. Current status and future prospects of transdermal drug delivery. Pharm Res 1996; 13(12): 1765-1769. http://dx.doi.org/ 10.1023/A:1016060403438 PMid:8987069

45. Hadgraft J, Pugh WJ. The selection and design of topical and transdermal agents: a review. J Inv Derm Symp Proc 1998: 3(2): 131135. http://dx.doi.org/10.1038/jidsymp.1998.27

46. Miller MA, Pisani E. The cost of unsafe injections. Bull World Health Organ 1997; 77: 808-811.

47. Glenn GM, Kenney RT. Mass vaccination: solutions in the skin. Curr Top Microbial Immunol 2006; 30: 247-268. http://dx.doi.org/10.1007/3540-36583-4 14

48. Zhao YL. Induction of cytotoxic T-lymphocytes by electroporationenhanced needle-free skin immunization 2006; 24: 1282-1290.

49. Ogura M, Paliwal S, Mitragotri S. Low-frequency sonophoresis: Current status and future prospects. Adv Drug Deliv Rev 2008; 3: 14-31.

50. Weniger BG, Papania M. Vaccines. Edn. $5^{\text {th }}$. Plotkn S, Orenstein W, Offit P, editors. Philadelphia: Elsevier 2008; 13: 1357-1392.

51. Chourasia MK, Jain SK. Polysaccharides for colon targeted drug delivery. Drug Del 2004; 11: 129-148. http://dx.doi.org/10.1080/ 10717540490280778 PMid: 15200012

52. Ardizzone S, Porro GB. Comparative tolerability of therapies for ulcerative colitis. Drug Saf 2002; 25(8): 561-582. http:// dx.doi.org/10.2165/00002018-200225080-00003

53. Minghetti P, Cilurzo F, Montanari L. Evaluation of adhesive properties of patches based on acrylic matrices. Drug Dev. Ind. Pharm 1999; 25(1): 1-6. http://dx.doi.org/10.1081/DDC-100102135 PMid:10028412

54. Spencer TS, Smith SE, Conjeevaram S. Adhesive interactions between polymers and skin in transdermal delivery systems. Poly. Mater. Sci. Eng 1990; 63: 337-339.

55. Wick KA, Wick SM, Hawkinson RW. Adhesion to skin performance of a new transdermal nitroglycerine adhesive patch. Clin. Therapeut 1989; 11(3): 417-424

56. Satas D. Handbook of Pressure Sensitive Adhesive Technology, third ed. Satas and Associates, Warwick, Rhode Island; 1999. p. 62-86.

57. Kim JH, Choi HK. Effect of additives on the crystallization and the permeation of Ketoprofen from adhesive matrix. Int. J. Pharm 23(1): 236-245.

58. Steven AJ, Atkins AG, Jeronimidis G, Vincent JF, Chivers RA. The effect of flexible substrates on pressure-sensitive adhesive performance. Int. J. Adhes 2002; 22: 423-430. http://dx.doi.org/10.1016/S01437496(02)00018-0

59. Vollmer U, Cordes G. Physical quality control of transdermal delivery systems. Int. Symp. Control. Rel. Bioact. Mater 1997; 24: 685-686.

60. Morishita M, Tanaka T, Takayame K. Usefulness of colon targeted DHA and EPA as novel diabetes medications that promote intrinsic GLP-1 secretion. Controlled release J 2008; 13: 99-104. http://dx. doi.org/10.1016/j.jconrel.2008.09.001 PMid:18804128

61. Eriane JA, Winter L. Comparison of the local tolerability and adhesion of a new matrix system (Menorest) for estradiol delivery with an established transdermal membrane system (Estraderm TTS), Maturitas 1997; 26: 95-101. http://dx.doi.org/10.1016/S0378-5122(96)01090-0

62. Gomez E, Williams M, Kunznicki JT, Myers WR, Zoller SA. Application and maintenance habits do make a difference in adhesion of Alora_transdermal systems, Maturitas 2000; 35: 58-70.

63. Chien YW. Novel Drug Delivery Systems; Transdermal Therapeutic Systems. Marcel Dekker, Inc., New York; 1982. p. 523-52.

\section{Cite this article as:}

Singh Mahavir, Sareen Rashmi. Transdermal drug delivery adhesion as a critical parameter. Int. Res. J. Pharm. 2013; 4(9):16-21 http://dx.doi.org/10.7897/2230-8407.04905 